\title{
Surface modification of polyethylene microplastic particles during the aqueous-phase ozonation process
}

\author{
Rabia Zafar, Seon Yeong Park, Chang Gyun Kim ${ }^{\dagger}$ \\ Department of Environmental Engineering, INHA University, Korea
}

\begin{abstract}
Microplastics coexist with the chemical reactive oxygen species in natural waters, however, there is still a lack to elucidate the effect of these radicals on the microplastic surficial oxidation. In this study, the ozonation of polyethylene microplastics was carried out under varying ozone dosages ranging from 4 to $7 \mathrm{mg} / \mathrm{min}$ for 60,120 and $180 \mathrm{~min}$, where its ozone uptake was iodometrically compared and surficial modification was spectroscopically analyzed using FTIR and XPS. For that, the lowest ozone uptake was $16 \%$ at $4 \mathrm{mg} / \mathrm{min}$ ozone supplied for $60 \mathrm{~min}$ whereas the highest was observed of $44 \%$ at $7 \mathrm{mg} / \mathrm{min}$ ozone added for $180 \mathrm{~min}$. Moreover, in the FTIR analysis, carbonyl $\left(1,600-1,800 \mathrm{~cm}^{-1}\right)$ and hydroxyl $\left(3,200-3,600 \mathrm{~cm}^{-1}\right)$ indices were improved more than $20 \%$ and $13 \%$ when they were ozonized at $7 \mathrm{mg} / \mathrm{min}$ for $180 \mathrm{~min}$ compared to $4 \mathrm{mg} / \mathrm{min}$ for $60 \mathrm{~min}$, respectively. XPS also revealed that $7 \mathrm{mg} / \mathrm{min}$ of ozone supplied for $180 \mathrm{~min}$ provided the highest of oxygen functionalities, but while there was no significant change in C-C bond. It can be concluded that the surficial modification of PE including formation of oxygen functionalities could be more preferably influenced by the reaction time than ozone dosages.
\end{abstract}

Keywords: FTIR, Microplastic, Ozonation, Polyethylene, X-ray photon spectroscopy

\section{Introduction}

The prevalence of microplastics (MPs) has been recently recognized as a threat to the biosphere owing to their infinitesimal size responsible for highly stable nature towards natural degradation processes $[1,2]$, thereby related adverse effects have been reported across all over ecosystems from low to high trophic levels of food chain: microorganisms [3-5], plants [6, 7], animals [8-11], and even human beings [12]. These significant ecological impacts persuade the researchers to investigate the aging behavior of these tiny particles in an environment. Till date, several studies have been conducted to determine the changes in physicochemical properties occurred as a result of physical, chemical $[13,14]$ and biological processes [14], moreover the requirement for the detailed research is obligatory.

In line with this, the advanced oxidation processes (AOPs) have been widely implemented and proven to be effective for the oxidation of plastics owing to the presence of reactive oxygen species including hydroxyl radicals, superoxide, peroxide, and atomic oxygen formed under a variety of chemical processes including ozonation [15, 16], persulfates activation [17], $\mathrm{UV} / \mathrm{O}_{3}[18], \mathrm{UV} / \mathrm{H}_{2} \mathrm{O}_{2}$ [19] and etc. Recently, the application of these technologies in the field MPs oxidation has gained attention for which several studies can be found in this regard. Briefly, Liu et al. studied the alteration properties of polystyrene (PS) and polyethylene (PE) MPs particles using chemical reagents such as potassium persulfate and Fenton reagent and observed the formation of oxygen functionalities on their surface [17]. Similarly, Mao et al. investigated the aging behavior of PS exposed to ultraviolet-A (UV-A) irradiation having an absorbance at $340 \mathrm{~nm}$ in the different environmental matrix (i.e., air, water, and sea water) [20], implying that the highest oxidation of the PS was detected in air matrix. In addition to, Tajkia et al. [21] observed an increase of $30 \%$ in carbonyl indices of low density polyethylene (LDPE) MPs treated under UV irradiation using zinc oxide $(\mathrm{ZnO})$ nanorods as a photocatalyst. These studies provide a clear evidence of applicability and effectiveness of AOPs for the alterations of MPs. Moreover, it eventually contributed to similar resultant owing to the involvement of conspecific radicals, although there are differences in their oxidation initiators [22]. Hence, the ozonation can be also one of the potential candidates for simulating the effect of reactive oxygen species on the surficial oxidation of MPs in the natural waters. Molecular ozone is a powerful
This is an Open Access article distributed under the terms of the Creative Commons Attribution Non-Commercial License (http://creativecommons.org/licenses/by-nc/3.0/) which permits unrestricted non-commercial use, distribution, and reproduction in any medium, provided the original work is properly cited.

Copyright (C) 2021 Korean Society of Environmental Engineers
Received July 23, 2020 Accepted October 04, 2020

${ }^{\dagger}$ Corresponding author

Email: cgk@inha.ac.kr

Tel: +82 328607561 Fax: +82 328601425

ORCID: 0000-0002-8668-3281 
oxidant with the oxidation potential of $2.07 \mathrm{~V}$ in a gaseous phase [23], making it turning into the hydroxyl radicals and other reactive oxygen species in an aqueous phase [24] and its polymeric oxidation have been investigated a lot $[23,25,26]$.

This is the first attempt to explore the effect of ozonation of PE MPs particles through an aqueous phase ozonation at 4 different ozone dosages (i.e., 4, 5, 6, and $7 \mathrm{mg} / \mathrm{min}$ ) for three different time durations of 60,120 , and 180 min. Herein, PE MP particles used was consisting of 5 different particle size range distribution: (i) < $75 \mathrm{~m}$ constitute $3.4 \%$ of sampled MPs; (ii) 75-125 $\mu \mathrm{m}, 7.2 \%$; (iii) $125-250 \mu \mathrm{m}, 43.0 \%$; (iv) 250-500 $\mu \mathrm{m}, 43.1 \%$; and (v) $>500 \mu \mathrm{m}$, $3.3 \%$, respectively, which were determined by multi-phase sieving. After that, the degree of oxidation of PE MPs was determined by Fourier transform infrared (FTIR) spectroscopy and X-ray photoelectron spectroscopy (XPS). This study should be helpful to elucidate the effect of the reactive oxygen species to MPs distributed in natural waters along with their surficial alteration.

\section{Materials and Methods}

\subsection{Ozonation of PE MP Particles}

The ozone treatment system was composed of ozone generation system and reaction chamber as presented in Fig. 1. Reaction chamber was equipped with two $300 \mathrm{~mL}$ Erlenmeyer flasks, which were served as the main ozonation chamber followed by ozone trapping equipment, respectively. Prior to the ozonation, the reaction mixture ( $\mathrm{pH} 6.59$ at $25^{\circ} \mathrm{C}$ ) was made of $1 \%(\mathrm{w} / \mathrm{v}) \mathrm{PE} \mathrm{MP}$ particles (medium density of $0.94 \mathrm{~g} / \mathrm{mL}$; melting point of $109-111^{\circ} \mathrm{C}$, Aldrich Chemical Co., USA) in distilled water and then infused into the main flask. It was continuously agitated on a magnetic stirrer set with a stirring speed of $100 \mathrm{rpm}$ under the ambient temperature to uniformly disperse PE MP particles during the treatment. Secondary flask was prepared by adding $100 \mathrm{~mL}$ of $1.2 \mathrm{M}$ potassium iodide (KI, Samchun Chemicals, Korea) solution to capture off-gas ozone which was released to be unreacted from the ozonation chamber. These two flasks were thoroughly capped by using a silicon stoppers and connected each other with the Pyrex tube (6.34 mm diameter, Koreel, Korea) to prevent ozone undesirably escaping. And thereafter, ozone was generated through dielectric barrier discharge (DBD) plasma [27] from the dry oxygen (Purity; 99.5-99.9\%) fed at a pressure of $1 \mathrm{MPa}$ into the ozone generator (Ozonetech, Korea). The ozone dosage was then adjusted to variably keep at 4, 5, 6 and $7 \mathrm{mg} / \mathrm{min}$ referring to the readings of ozone gas analyzer (H1 Series Ozone Analyzers, INUSA ${ }^{\mathrm{TM}}$, USA). They were immediately entered into the reaction chamber where PE MP particles were oxidized for varying times of 60, 120 and $180 \mathrm{~min}$. After the termination of each experiment, the treated PE MPs were separated using $0.45 \mu \mathrm{m}$ cellulose acetate membrane filter (ADVANTEC $^{\circledR}$, Tokyo Roshi Kaisha Ltd., Japan) to analyze the possible surficial modification followed by being dried for $24 \mathrm{~h}$ in a drying oven $\left(50^{\circ} \mathrm{C}\right.$, Vision Scientific Co., Ltd., Korea), which were then stored in vacuum desiccator at room temperature for further surface analysis of FTIR and XPS.

\subsection{Measurement of Ozone Uptake by PE MP Particles}

The off-gas of ozone released during the oxidation of PE MP particles was captured by KI solution in the off-gas ozone trap, which were used to measure the extent of the flow rates of ozone gassed out and ozone uptake by PE MP particles. First, the flow rate was determined by modified iodometric titration method [17, 28], where the residual ozone reacted with iodide ion $\left(\mathrm{I}^{-}\right)$to form iodine $\left(\mathrm{I}_{2}\right)$.

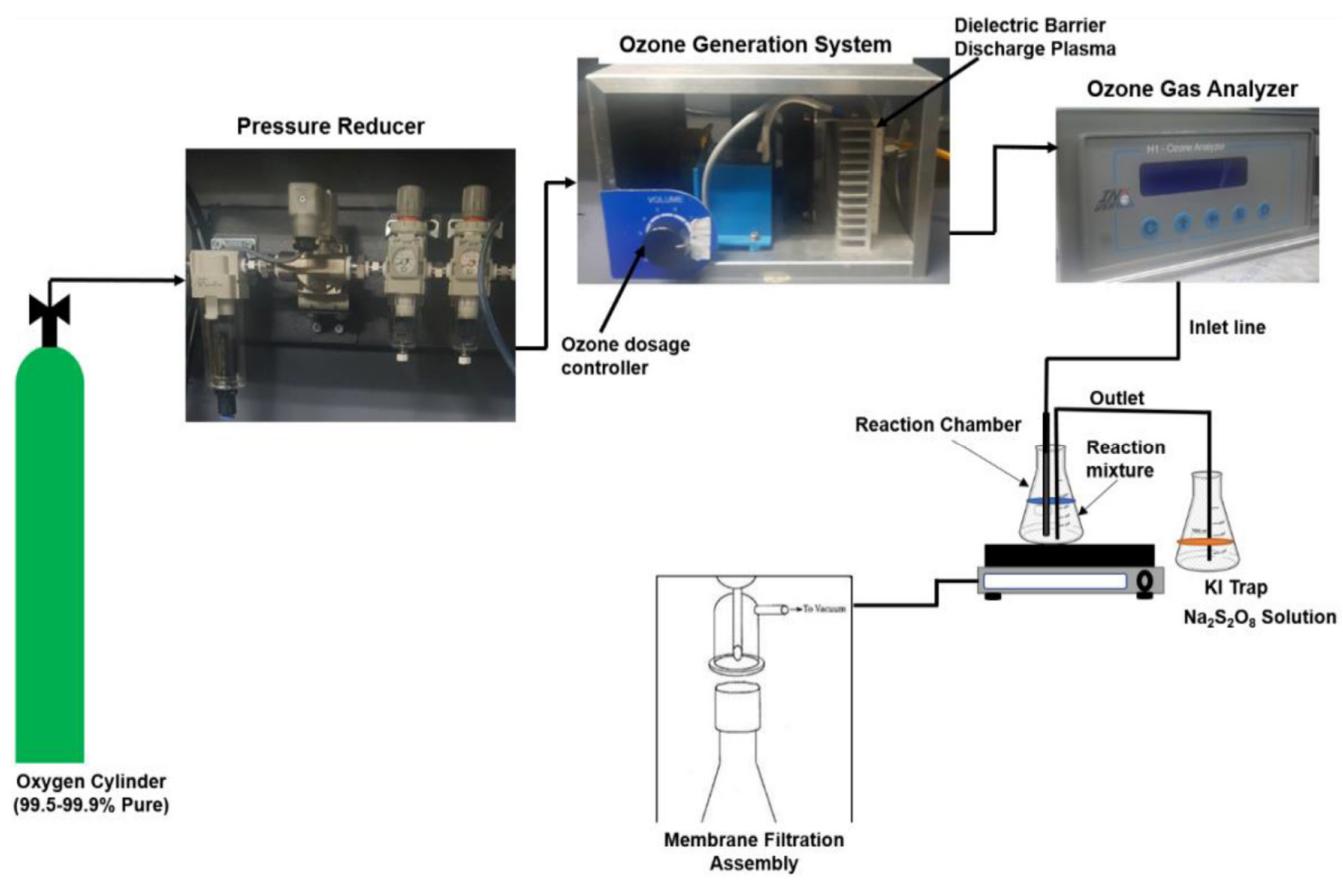

Fig. 1. Schematic diagram of ozone oxidation process on PE MP particles constituting of ozone generation system and reaction chamber. 
Briefly, $10 \mathrm{~mL}$ of $\mathrm{KI}$ solution captured off-gas ozone was mixed with $5 \mathrm{~mL}$ of $2 \%(\mathrm{w} / \mathrm{v})$ of sulfuric acid (95\%, Samchun Chemicals, Korea) solution and the mixture was then titrated with standardized sodium thiosulfate solution $\left(0.001 \mathrm{~N}, \mathrm{Na}_{2} \mathrm{~S}_{2} \mathrm{O}_{3} .5 \mathrm{H}_{2} \mathrm{O}\right.$, Daejung Chemical, Korea) till pale yellow color appeared. After that, $1 \mathrm{~mL}$ of $1 \%(\mathrm{w} / \mathrm{v})$ of starch $\left(\left(\mathrm{C}_{6} \mathrm{H}_{10} \mathrm{O}_{5}\right) n\right.$, Duksan Chemicals, Korea) indicator was added, which were then secondary titrated till color changed from blue to colorless. From that, the total volume of sodium thiosulfate solution consumed for titration was recorded, from which the flow rate $\left(\mathrm{O}_{3}\right.$, off-gas $)$ was calculated by using the Equation (1), presented by Chtourou et al. [15]:

$$
\mathrm{O}_{3, \text { off-gas }}(\mathrm{mg} / \mathrm{min})=\frac{(A \times N \times B \times 24)}{(t \times V)}
$$

Where, A is the volume of sodium thiosulfate solution used for titration $(\mathrm{mL}), \mathrm{B}$ is the total volume of KI solution used to capture ozone $(100 \mathrm{~mL}), \mathrm{V}$ is the volume of $\mathrm{KI}$ used for titration $(10 \mathrm{~mL}), \mathrm{N}$ is the normality of sodium thiosulfate solution $(0.001$ $\mathrm{N}$ ), and $\mathrm{t}$ is the ozonation time (min). It was converted to the flow rate of off-gas ozone by multiplying the conversion factor of 24. After that, the percentage ozone uptake by PE MP particles was also determined by Equation (2), with the off-gas ozone flow rate obtained under the presence $\left(\mathrm{O}_{3}, \mathrm{pE}\right)$ over absence $\left(\mathrm{O}_{3}\right.$, Blank $)$ of $\mathrm{PE}$ particles in the reaction chamber, respectively.

$$
\text { Ozone uptake }(\%)=\frac{\left[O_{3, \text { Blank }}\right]-\left[O_{3, P E}\right]}{O_{3, \text { Blank }}} \times 100
$$

\subsection{Fourier Transform Infrared (FTIR) Spectroscopy}

For the first time, a pellet was made by grinding a mixture of $100 \mathrm{mg}$ of potassium bromide (KBr, FTIR grade, Merck, Germany) and $5 \mathrm{mg}$ of oxidized PE MP particles in an agate mortar followed by pelletizing with Altas ${ }^{\mathrm{TM}}$ manual hydraulic press (SPECAC Inc., USA). The surface modification of those pellets of PE MP particles after ozonation at 4 different ozone dosages for three different time reactions was analyzed by FTIR (VERTEX 80V, Bruker, Germany) in the wavenumber ranging from $4,000 \mathrm{~cm}^{-1}$ to $400 \mathrm{~cm}^{-1}$ with a resolution of $4 \mathrm{~cm}^{-1}$. The obtained numbers of FTIR spectra were corrected by baseline method [29] and then normalized to the band at the wavenumber of $1,472 \mathrm{~cm}^{-1}(\mathrm{C}=\mathrm{C}$, double bond stretching) because it was to be unchangeably sustained as of that of virgin PE peak even though PE particle has been oxidized, otherwise rest of those peaks having been changed after the oxidation. From these normalized spectra, the degree of carbonyl and hydroxyl indices were determined by integrating the peak areas in between 1,600-1,800 $\mathrm{cm}^{-1}$ and 3,200-3,600 $\mathrm{cm}^{-1}$, respectively, using a linear end-to-end baseline approach.

In the meantime, the crystallinity of PE MPs was estimated as suggested by Zerbi et al. [30]. Namely, comparing peak height at $730 \mathrm{~cm}^{-1}$ (corresponding to crystalline content) versus $719 \mathrm{~cm}^{-1}$ (amorphous content) can obtain the percentage of crystalline phase content as calculated by the following Eq. (3):

$$
\text { Crystalline phase content }(\%)=\left[1-\frac{\left.\left\{1-\left(I_{730} / I_{719}\right) / 1.233\right)\right\}}{\left(1+I_{730} / l_{719}\right)}\right] \times 100(3)
$$

Where, $I_{730}$ and $I_{719}$ are the respective absorbance intensity of peak at $730 \mathrm{~cm}^{-1}$ and $719 \mathrm{~cm}^{-1}$ in the normalized FTIR spectra, and 1.233 is the theoretical intensity ratio of at the settling angle of $42^{\circ}$.

\subsection{X-ray Potoelectron Spectroscopy (XPS)}

X-ray photoelectron spectra of PE MP samples were determined using XPS (K-Alpha, Thermo scientific, USA) equipped with monochromatic AI-Ka source. From this, low resolution spectrum (0 to $1,200 \mathrm{eV}$ of binding energy) was used to monitor possible changes of elemental concentrations such as sodium $(\mathrm{Na})$, silicone $(\mathrm{Si})$, and nitrogen $(\mathrm{N})$, along with the determination of ratio of oxygen to carbon $(\mathrm{O} / \mathrm{C})$, while high-resolution spectra for $\mathrm{C} 1$ s region $(280$ to $293 \mathrm{eV}$ ) and O1s region (526-538 eV) were deconvoluted into subpeaks by Origin software (OriginPro 9.0, Electronic Arts, USA) to distinct the type of carbon-oxygen functionalities newly appeared on the PE surface since after the ozonation.

\section{Results and Discussion}

\subsection{Ozone Uptake by PE MPs}

The flow rate of off-gas ozone released during ozonation was determined using Eq. (1) and thereafter, compared in the presence (the test) over the absence (i.e., the control) of PE MP particles under the given experimental conditions of 4 different ozone dosages and 3 different reaction times, as presented in Fig. 2. It showed that the flow rate was continuously declined in both control and test samples as the inlet ozone dosages was increased from 4 to $7 \mathrm{mg} / \mathrm{min}$ for each reaction time: for the control samples, it was decreased from 3.5 to $1.2 \mathrm{mg} / \mathrm{min}$ just since after $60 \mathrm{~min}$, from 2.9 to $1.0 \mathrm{mg} / \mathrm{min}$ immediately after $120 \mathrm{~min}$, and from 2.5 to $0.8 \mathrm{mg} / \mathrm{min}$ after $180 \mathrm{~min}$, respectively. It was also confirmed that the prolonged treatment duration made off-gas ozone flow rate much furtherly decreased. It can be attributed to ozone decomposition by $\mathrm{OH}, \mathrm{HO}_{2}^{-}, \mathrm{O}_{2}^{-}$radical $\left({ }^{\bullet} \mathrm{O}_{2}^{-}\right)$and ozone itself $(\mathrm{pH} 6.59$ at $25^{\circ} \mathrm{C}$ ), as suggested in Eq. (4)-(7) [25, 26, 28]. These reactions depicted that ozone decomposition could be accelerated as the ozone dosage and the reaction time increased, more promoting the generation of superoxide anion $\left({ }^{\bullet} \mathrm{O}_{2}^{-}\right)$with a much higher reaction rate of $1.6 \times 10^{9} \mathrm{M}^{-1} \mathrm{~s}^{-1}$ (Eq. (6)) involved in ozone decomposition, consequently leading to decrease of the off-gas ozone flow rate.

$$
\begin{array}{ll}
\mathrm{O}_{3}+\mathrm{OH}^{-} \rightarrow \mathrm{HO}_{2}^{-}+\mathrm{O}_{2} & \mathrm{k}_{1}=70 \mathrm{M}^{-1} \mathrm{~s}^{-1} \\
\mathrm{O}_{3}+\mathrm{HO}_{2}^{-} \rightarrow \mathrm{O}^{-}+\mathrm{HO}_{2}^{\bullet} & \mathrm{k}_{2}=2.8 \times 10^{6} \mathrm{M}^{-1} \mathrm{~s}^{-1} \\
\mathrm{O}_{3}+{ }^{\bullet} \mathrm{O}_{2}^{-} \rightarrow{ }^{\bullet} \mathrm{O}_{3}^{-}+\mathrm{O}_{2} & \mathrm{k}_{3}=1.6 \times 10^{9} \mathrm{M}^{-1} \mathrm{~s}^{-1} \\
\bullet^{-} \mathrm{O}_{3}^{-}+\mathrm{H}_{2} \mathrm{O} \rightarrow{ }^{\bullet} \mathrm{OH}+{ }^{-} \mathrm{OH}+{ }^{\bullet} \mathrm{O}_{2} & \mathrm{k}_{4}=20-30 \mathrm{M}^{-1} \mathrm{~s}^{-1}
\end{array}
$$

In the meantime, Fig. 3 showed that as higher as ozone dosage and as long as the reaction time could make the higher percentage of ozone uptake to be evident by comparing the control over the test of off-gas ozone flow rate: the ozone uptake by PE MP particles 

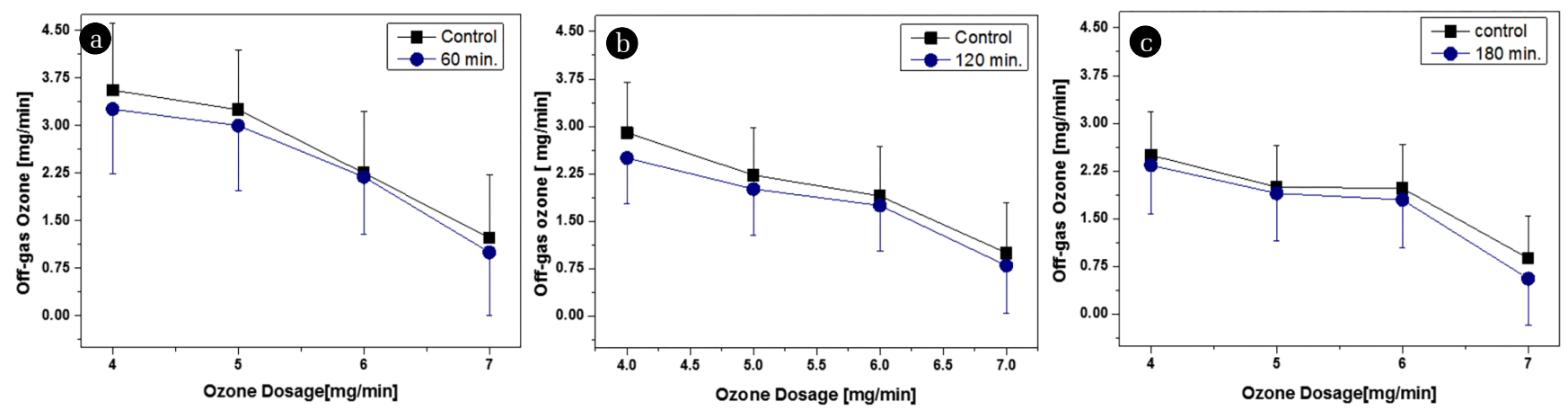

Fig. 2. The comparison of off-gas ozone flow rate in the presence/absence of PE MP particles under the given inlet ozone dosages of 4 , 5 , 6, and $7 \mathrm{mg} / \mathrm{min}$ for (a) $60 \mathrm{~min}$, (b) $120 \mathrm{~min}$, and (c) $180 \mathrm{~min}$, respectively.

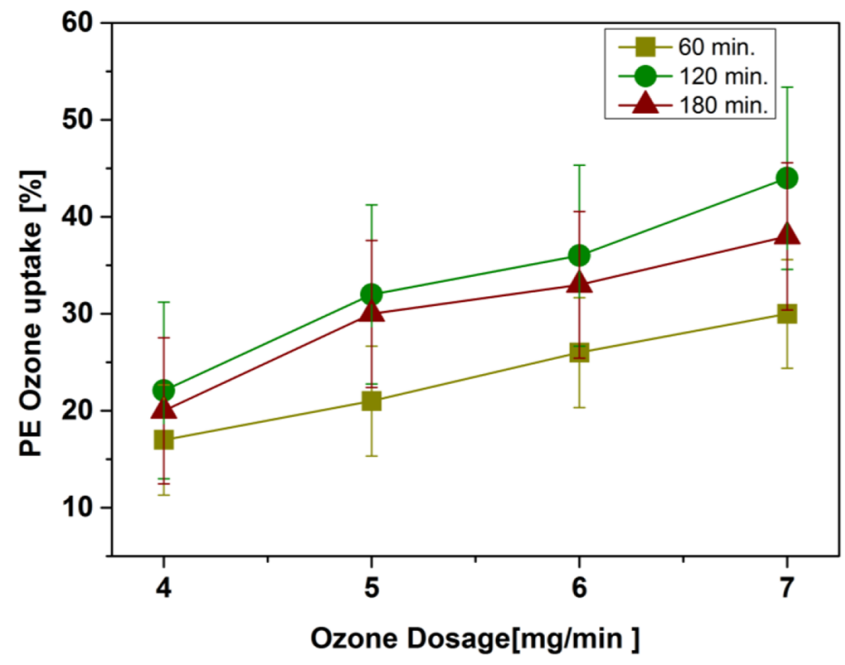

Fig. 3. Percentage ozone uptake by PE MP particles during the ozonation at the ozone dosage of $4,5,6$, and $7 \mathrm{mg} / \mathrm{min}$ for 60,120 , and $180 \mathrm{~min}$.

has been increased at the lowest to be $16 \%$ (injected ozone of $4 \mathrm{mg} / \mathrm{min}$ for $60 \mathrm{~min}$ ), while at the highest to be $44 \%$ (7 mg/min; $180 \mathrm{~min}$ ). Moreover, it was presumed that the MP oxidation could be triggered as of a result of ozone uptake by PE MP particles. In other words, relatively lower dosage for shorter reaction time could be served as initiating oxidation of PE MP particles, which could be slightly enhanced by increasing the amount of ozone dosage at the same reaction time (i.e., $60 \mathrm{~min}$ ). On the contrary, extending the reaction time longer than $60 \mathrm{~min}$ at the same dosage could more increase the extent of oxidation of those of particles. It therefore implied that the reaction time can be considered as the key factor in the uptake of ozone by PE MP particles, whereas the ozone dosage might be served as a potential factor contributing in ozonation of them.

\subsection{FTIR Analysis of Ozonized PE MP Particles}

\subsubsection{FTIR Spectra of treated PE MP particles}

FTIR spectra (Fig. S1) showed that ozonation has generated new functionalities on the surface of PE MP particles at the wavenumber of $1,030 \mathrm{~cm}^{-1}$ (C-O), 1,652 $\mathrm{cm}^{-1}$ (R-CHO with intermolecular
H-bond), 1,683 $\mathrm{cm}^{-1}$ (R-CO-OR'), 1,718 and 1,720 $\mathrm{cm}^{-1}$ (RC(=O)R') irrespective of varying dosages and reaction times, whereas the peaks for vinyl group (900-1,000 $\left.\mathrm{cm}^{-1}\right)$ was not observed. In particular, the absorption band at $1,720 \mathrm{~cm}^{-1}(>\mathrm{C}=\mathrm{O}$, stretching ketonic group) reflects to the strong probability of aliphatic aldehydes, carboxylic acid and aliphatic ketones being occurred [31] as well as smaller amount of carboxyl groups as of intermediates [32]. In addition to, Kefeli et al. [33] reported that the ozonation of such saturated hydrocarbon chains forms peroxy-radicals, which is then converted into peroxides, ketones, and aldehydes [34-36]. In other words, the appearance of these functionalities suggested by the fact that peroxy radicals formed on the polymeric chain of PE MP particles due to the attack of ozone and its derivates (i.e., reactive oxygen species) [28], furtherly generates hydroperoxides, ketones and alcohols [37], as presented in following Eq. (8)-(10):

$$
\begin{gathered}
\mathrm{RH}+\mathrm{O}_{3} \rightarrow \mathrm{ROO}^{\bullet}+{ }^{\bullet} \mathrm{OH} \\
2 \mathrm{ROO}^{\bullet}+\mathrm{RH} \rightarrow \mathrm{ROOH}+\mathrm{R}^{\bullet} \\
2 \mathrm{ROO}^{\bullet} \rightarrow \mathrm{RC}=\mathrm{O}+\mathrm{RC}-\mathrm{OH}+\mathrm{O}_{2}
\end{gathered}
$$

Besides, a broad absorption band between 1,100 to $1,200 \mathrm{~cm}^{-1}$ could be resulted from the overlapping of different absorption groups including such as alcohols, esters, ethers and acids [38], which were also attributed to the attack of $\mathrm{OH}^{-}, \mathrm{HO}_{2}^{-}$and $\mathrm{O}_{2}^{-}$on the surface of the PE MP particles. The generated $\mathrm{OH}^{-}$played a role of initiator in the oxidation process by abstracting hydrogen atoms from the polymeric chain, leading to the formation of alkyl radicals (Equation (11)) which can eventually result in the generation of oxygenated functionalities. In addition to, they are responsible for the formation of $\mathrm{O}_{2}^{-}$under the presence of promoters (e.g., ozone and primary alcohol) inducing the surficial oxidation of PE MP particles [26].

$$
\mathrm{RH}+{ }^{\bullet} \mathrm{OH} \rightarrow \mathrm{H}_{2} \mathrm{O}+\mathrm{R}^{\bullet}
$$

In line with, the appearance of these carbon-oxygen functionalities is served as the major indicator of changes taken place from oxidatively deformed polymers [39] which can in turn provide 
the evident clue for their possible oxidative modifications occurred referring to the Norrish type I and II reactions. The Norrish type I reaction (Fig. S2 (a)) produces acyl and alkyl radicals. The acyl radicals further react with oxygen to produce polymer peracid radicals and followed by polymer peracids abstracting hydrogen. These polymer peracids can breakdown into hydroxyl radicals and polymer carboxyl radicals eventually converting into carbonyls together with other functional groups. This reaction may be terminated via crosslinking. Whereas, in Norrish type II reaction (Fig. S2 (b)), the hydrogen is abstracted from a $\curlyvee$ carbon or polymeric chain-end is decomposed to generate carbonyl and vinyl groups [29].

In the meantime, the broad absorption peaks observed between $3,400-3,600 \mathrm{~cm}^{-1}$ or at $1,377 \mathrm{~cm}^{-1}$ commonly assigned to the $\mathrm{O}-\mathrm{H}$ bond of the alcohol groups. They might be arisen due to the reaction with another alkyl radicals which can produce double bond/crosslink, or reaction with the other reactive oxygen species leading to the formation of $\mathrm{OH}$-containing functionalities such as alcohols and hydroperoxide on the surface of PE [38]. In particular, the peak height corresponded at the wavenumber of $3,555 \mathrm{~cm}^{-1}$ was appeared to be formed by the presence of hydroperoxides [40], ultimately contributing to the generation of various functional groups such as ketones [41] and concomitantly providing the active sites for the further oxidation process of PE [34].

\subsubsection{Carbonyl index (CI)}

As aforementioned, carbonyl groups, in this study, were likely to be occurred on the surface of PE MP particles through Norrish Type I reaction, since the newly appearance of vinyl groups was not found in the FTIR spectra. They were significantly increased once ozone injected in comparison with those of control, clearly implying that these oxidized functionalities (i.e., ketones and esters) were generated by the attack of radicals. For this reason, the carbonyl indices (CIs) of each treated PE MP particles were compared by calculating based on the suggested methodology in section of 2.3 .

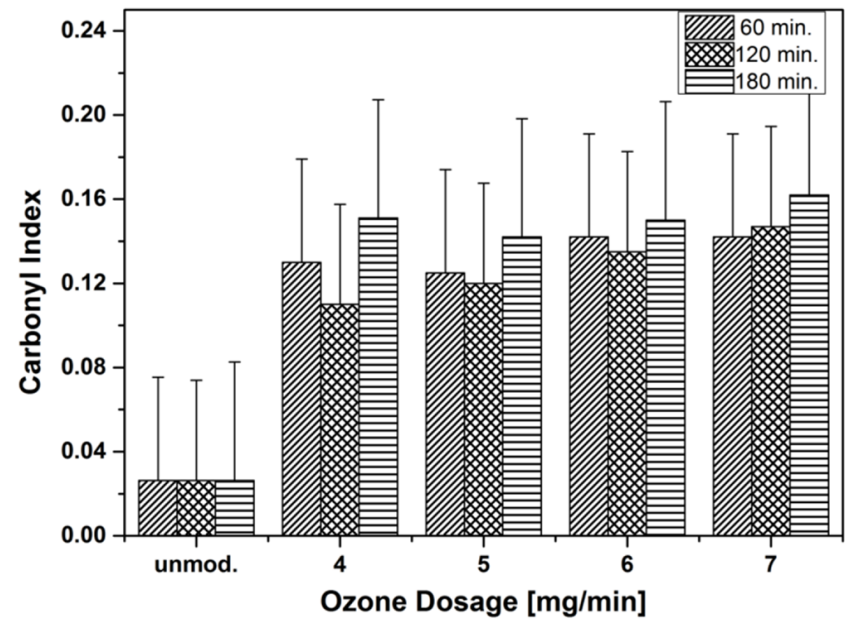

Fig. 4. The variation of carbonyl index $\left(\mathrm{Cl}, 1,600-1,800 \mathrm{~cm}^{-1}\right)$ estimated from the FTIR spectra for various ozone dosages and different treatment times in terms of $4,5,6$, and $7 \mathrm{mg} / \mathrm{min}$ for 60,120 , and $180 \mathrm{~min}$ normalized to the reference absorption band at $1,472 \mathrm{~cm}^{-1}$.
As can be seen in Fig. 4, CI value for $180^{\text {th }}$ min was tended to be remarkably increased as the ozonation has been initiated, which was then furtherly escalated to the highest value of $20 \%$ at the ozone dosed at $7 \mathrm{mg} / \mathrm{min}$, even though their degrees of increment were relatively small in the comparison with those of other literatures to be observed [32, 42]. Nevertheless, it was comparably implied that shorter reaction time may not effectively facilitate in deriving that much of increase in the CIs comparing to that of the longer reaction time. It might be ascribed to the fact that tight molecular arrangement still firmly resisted against those of given shorter time of reaction, which in turn could make the longer treatment duration to be needed to furtherly oxidize.

\subsubsection{Hydroxyl index (HI)}

Fig. 5 presented the changes in hydroxyl index (HI) of PE MP particles after the ozonation treatment under 4 different dosages and three different reaction times, and it showed an overall increasing trend of HIs (approx. 13\%) for a relatively longer treatment duration (i.e., 120 and $180 \mathrm{~min}$ ), while shorter reaction for 60 min rather led to decreasing the $\mathrm{HI}$ values, even though ozone has been increasingly injected as high as $7 \mathrm{mg} / \mathrm{min}$ into the reaction. It simply meant that the higher increase of those of index for longer reaction time could be obviously justified by the fact that there have been more extent of generation of hydroperoxides resulting from such escalating ozone dosages and longer reaction time, which can be consequently subject to more conversion of carbonyl groups, as previously described. However, in the case of $60 \mathrm{~min}$, HI had a decreasing trend despite of the increment of ozone dosages, because there might be not given enough reaction time to be consumed to form the amount of hydroperoxides demanded in modifying that of PE surfaces, even at $7 \mathrm{mg} / \mathrm{min}$ of inlet ozone dosage. Therefore, longer time duration could be more predominant controlling factor rather than that of ozone dosage in more significantly breaking down the surficial chemical structure of PE MP particles.

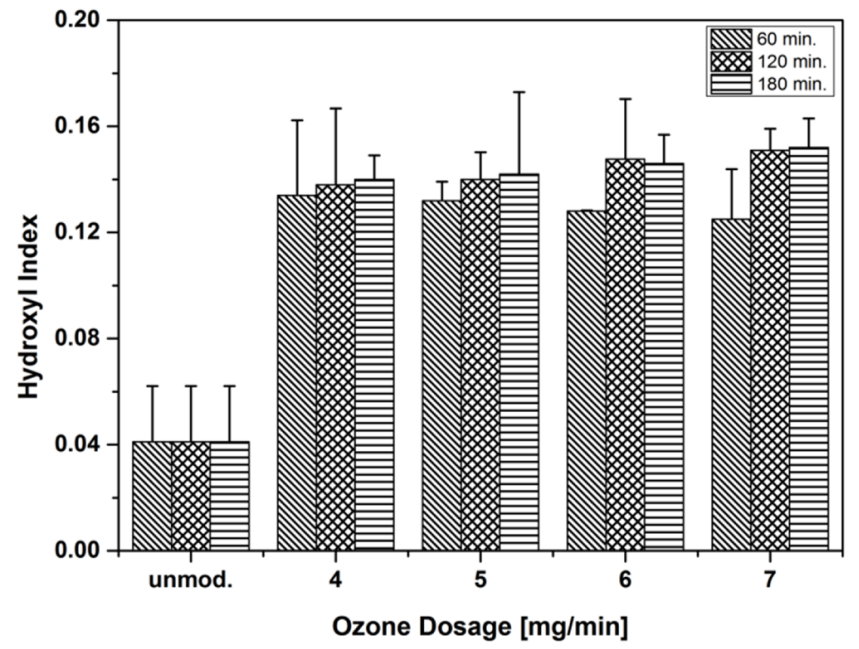

Fig. 5. The variation of hydroxyl index $\left(\mathrm{HI}, 3,200-3,600 \mathrm{~cm}^{-1}\right)$ for various ozone dosages and different treatment times in terms of 4, 5, 6 , and $7 \mathrm{mg} / \mathrm{min}$ for 60, 120, and $180 \mathrm{~min}$ estimated from normalization with reference band of $1,472 \mathrm{~cm}^{-1}$. 


\subsubsection{Crystallinity}

Owing to their semi-crystalline structure [43], the crystallinity of PE MP particles has been changed during the surficial modification to be progressed. Chain scission resulting from Norrish I or II reactions reduces the entanglement density in amorphous phase, which allows for the shorter chained molecules to be more freely loosened and to recrystallize each of the loosened again to be attracted [39], consequently contributing to increase of crystallinity. On the contrary, the crosslinking mainly occurred by Norrish type I reaction decrease the crystallinity of polymer materials. In this study, the crystallinity has been declined all experimental conditions, in terms of 4 different dosages and three different reaction times, compared to that of unmodified (Fig. 6), implying that the Norrish type I reaction accompanied by crosslinking has been involved in the surface modification of PE MP particles, as aforementioned. Moreover, the relatively more prolonged reaction time could induce to the more inconsistent decrease of crystallinity in comparison with the shorter of $60 \mathrm{~min}$. It is presumably supposed that the crosslinking between the PE molecules has been correspondingly broken down as a result of ozone uptake being increased to agreeably attack PE MP particles for relatively longer time.

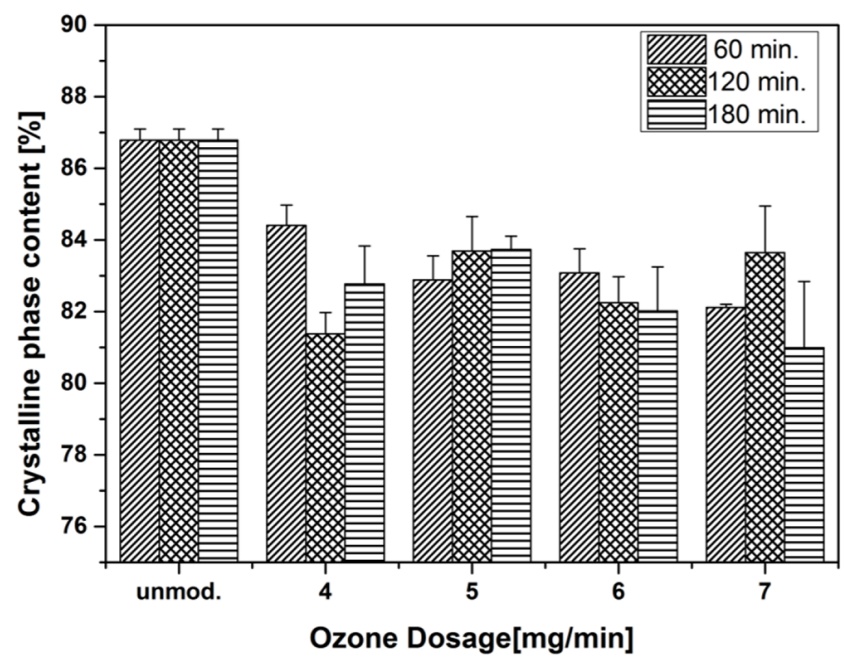

Fig. 6. The variation of crystallinity for various ozone dosages and different treatment times in terms of 4, 5, 6, and $7 \mathrm{mg} / \mathrm{min}$ for 60,120 , and 180 min comparing to that of unmodified PE MP particles.

\subsection{X-ray Photoelectron Spectroscopy}

In order to get the clear information for variation of the carbon-oxygen functionalities on PE MP surface after the ozone treatment for 180 min under the given 4 different ozone dosages, XPS spectra of them were comparatively analyzed with low- (Fig. S3) and high-resolution scan modes (Fig. 7), respectively. First, low-resolution scan modes for the control as of the unmodified and the treated $\mathrm{PE}$ particles were compared to each other with respect to their elemental composition and $\mathrm{O} / \mathrm{C}$ ratio, which could distinguish to examine their possible surface oxidation to be occurred (Table 1). From this, carbon (C) and oxygen (O) were majorly detected along with a relatively small quantities of sodium $(\mathrm{Na})$, nitrogen $(\mathrm{N})$, and silicon $(\mathrm{Si})$, which can be possibly derived from the plastic additives used in the manufacturing process. The $\mathrm{O} / \mathrm{C}$ ratio of ozonated PE MP particles was gradually increased as higher as ozone dosage was applied, evidently indicating that the surface oxidation of PE has been associated into instigating more hydrophilic nature.

Second, to further explain the changes occurring on the PE surface, high resolution scans of the O1s and C1s region were obtained under four different ozone dosages as aforementioned, which were then deconvoluted into three sub-peaks of at the binding energy of $531 \mathrm{eV}(\mathrm{O}-\mathrm{H}), 533 \mathrm{eV}(\mathrm{C}-\mathrm{O} / \mathrm{C}=\mathrm{O})$ and $534.5 \mathrm{eV}(\mathrm{O}-\mathrm{C}=\mathrm{O})$ in the case of O1s region (Fig. 7 (a)-(e)), and $285 \mathrm{eV}(\mathrm{C}-\mathrm{C} / \mathrm{C}-\mathrm{H})$, $286.5 \mathrm{eV}(\mathrm{C}-\mathrm{OH})$, and $288 \mathrm{eV}(\mathrm{C}=\mathrm{O})$ for $\mathrm{C} 1$ s region (Fig. 7 (f)-(j)), respectively. In regard to the $\mathrm{O} 1 \mathrm{~s}$ region, $\mathrm{O}-\mathrm{H}$ and $\mathrm{C}-\mathrm{O}$ bonds were initially formed in all PE MP particles ozonated, readily changed into $\mathrm{C}=\mathrm{O}$, which were further converted into $\mathrm{O}-\mathrm{C}=\mathrm{O}$ groups, depending on the inlet ozone dosages. For instance, it was observed that $\mathrm{O}-\mathrm{H}$ groups are more dominantly formed on the surface of $\mathrm{PE}$ particles along with little amount of $\mathrm{C}=\mathrm{O} / \mathrm{C}-\mathrm{O}$ even at $4 \mathrm{mg} / \mathrm{min}$ (Fig. 7 (b)). Further increasing ozone dosage initiated to convert $\mathrm{O}-\mathrm{H}$ groups into carbonyl groups (Fig. 7 (c)) and consequently generated $\mathrm{O}-\mathrm{C}=\mathrm{O}$ groups at $7 \mathrm{mg} / \mathrm{min}$ (Fig. 7 (e)), being in agreement with the result of ozone uptake and FTIR analysis. Likewise, the deconvoluted C1s region (Fig. 7 (g)-(j) showed the increase in the degree of intensity of $\mathrm{C}-\mathrm{OH}$ groups, whereas that of $\mathrm{C}-\mathrm{C}$ bond was not significantly changed during ozonation process. It implied that surficial change occurs only in the amorphous region, not crystalline region where ozone hardly to penetrate, which has been verified from previous scientific publications [32].

On the other hand, the overall experimental data delineates that as greater as ozone dosage and as longer as treatment time can more favor the extent of oxidation process to be more taken

Table 1. The Percentage of Element Composition of PE Particles and Their O/C Ratio from the Low-resolution Spectra of XPS after the Ozonation for $180 \mathrm{~min}$

\begin{tabular}{|c|c|c|c|c|c|}
\hline \multirow{2}{*}{ Element } & \multirow{2}{*}{ Unmodified PE } & \multicolumn{4}{|c|}{ Ozone Dosages } \\
\hline & & $4 \mathrm{mg} / \mathrm{min}$ & $5 \mathrm{mg} / \mathrm{min}$ & $6 \mathrm{mg} / \mathrm{min}$ & $7 \mathrm{mg} / \mathrm{min}$ \\
\hline $\mathrm{Na}$ & 0.12 & 0.18 & 0.13 & 0.11 & 0.22 \\
\hline $\mathrm{N}$ & 0.11 & 0.23 & 0.62 & 0.82 & 1.88 \\
\hline $\mathrm{Si}$ & 0.10 & 0.22 & 0.39 & 1.09 & 1.67 \\
\hline $\mathrm{O}$ & 2.5 & 2.9 & 3.3 & 3.6 & 3.9 \\
\hline $\mathrm{C}$ & 96.7 & 96.28 & 94.68 & 94.66 & 92.21 \\
\hline $\mathrm{O} / \mathrm{C}$ & 0.025 & 0.030 & 0.034 & 0.038 & 0.042 \\
\hline
\end{tabular}



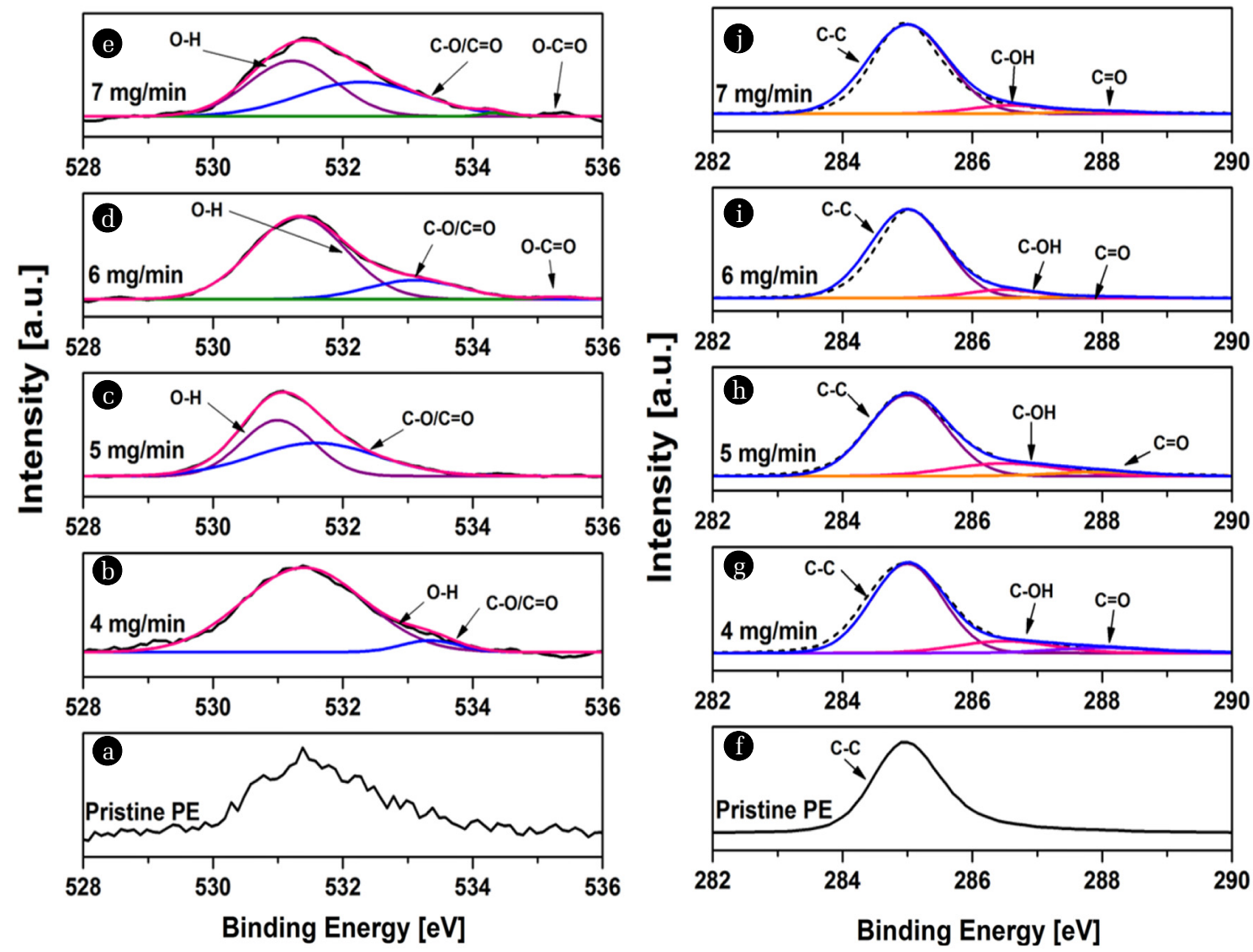

Fig. 7. The comparative study of deconvoluted peaks for the control and the tested by high resolution spectra of $\mathrm{O} 1 \mathrm{~s}$ into $\mathrm{O}-\mathrm{H}, \mathrm{C}-\mathrm{O} / \mathrm{C}=\mathrm{O}$ (a-e) and $\mathrm{C} 1 \mathrm{~s}$ into $\mathrm{C}-\mathrm{C}, \mathrm{C}-\mathrm{OH}$ and $\mathrm{C}=\mathrm{O}(\mathrm{f}-\mathrm{j})$, respectively.

place on the MP particles. However, in XPS result, it was observed that the relatively lower ozone dosage supplied to the reaction chamber, 4 and $5 \mathrm{mg} / \mathrm{min}$, clearly favors the more increased formation of hydroxyl radicals [23], from which more than those of dosages further added were still kept in increasing to the level of the radicals although the ozone uptake was much higher increased. It was also demonstrated that ozonation of PE has a slow initiation stage due to tight packing of its polymer molecules, which require a longer treatment time (at least 6 to $8 \mathrm{~h}$ ) for the penetrating into the crystalline region to break down the polymeric chain. In this aspect, the treatment duration of 180 min could be also still insufficient to effectively breaking down the polymeric chains or innovatively change the surface morphology of those.

\section{Conclusion}

In this study, PE MP particles were ozonated under the given ozone injection conditions in terms of varying ozone dosages and reaction time along with taking consideration for the quantification of ozone uptake to investigate any possible surface chemical modifications on PE MP particles as examined by the FTIR and XPS analyses. To sum up, it was concluded that shorter treatment duration was insufficient to support the higher ozone uptake by PE MPs, while increasing reaction time can enhance the level of ozone uptake rate and the degree of oxidation as having been verified with the CI, HI and crystallinity together with the variation in carbon-oxygen functionalities. These parameters overall indicated that the surface oxidation in the aqueous phase was mainly attributed to the attack of reactive oxygen species generated from ozone decomposition, which can make various functional groups on PE MP particles via Norrish type I reaction accompanied by crosslinking. In line with this, the optimum dosage and duration time were determined with $7 \mathrm{mg} / \mathrm{min}$ and $180 \mathrm{~min}$, having a highest value of CI and HI while a lowest crystallinity after the surface modification of PE MP particles. Nevertheless, further research will be necessarily conducted to enhance the level of oxidation performance which can lead to more increasingly breaking down MP in natural waters.

\section{Acknowledgment}

This research was a part of project titled "Development of a water treatment system to remove harmful substances from ecological disturbances emitted from quarantine stations such as imported fishery products (No. 20180341)" supported by Korea Institute of Marine Science and Technology Promotion and funded by the Ministry of Oceans and Fisheries (MOF). 


\section{Author Contributions}

R.Z. (M.S. student) designed and conducted the experiment along with data analysis and writing of the manuscript. S.Y.P (Ph.D. student) edited the manuscript and provided the critical feedback and contributed to shape the research study. C.G.K (Professor) approved all the experimental results and modified the manuscript.

\section{References}

1. Von Moos N, Burkhardt-Holm P, Köhler A. Uptake and effects of microplastics on cells and tissue of the blue mussel Mytilus edulis L. after an experimental exposure. Environ. Sci. Technol. 2012;46:11327-11335.

2. Masura J, Baker JE, Foster GD, Arthur C, Herring C. Laboratory methods for the analysis of microplastics in the marine environment: recommendations for quantifying synthetic particles in waters and sediments. 2015.

3. Sun X, Chen B, Li Q, et al. Toxicities of polystyrene nano-and microplastics toward marine bacterium Halomonas alkaliphila. Sci. Total Environ. 2018;642:1378-1385.

4. Nomura T, Tani S, Yamamoto M, et al. Cytotoxicity and colloidal behavior of polystyrene latex nanoparticles toward filamentous fungi in isotonic solutions. Chemosphere 2016;149:84-90.

5. Graham ER, Thompson JT. Deposit-and suspension-feeding sea cucumbers (Echinodermata) ingest plastic fragments. J. Exp. Mar. Bio. Ecol. 2009;368:22-29.

6. Bhattacharya P, Lin S, Turner JP, Ke PC. Physical adsorption of charged plastic nanoparticles affects algal photosynthesis. J. Phys. Chem. C. 2010;114:16556-16561.

7. Kalčíková G, Žgajnar GA, Kladnik A, Jemec A. Impact of polyethylene microbeads on the floating freshwater plant duckweed Lemna minor. Environ. Pollut. 2017;230:1108-1115.

8. Martínez-Gómez C, León VM, Calles S, Gomáriz-Olcina M, Vethaak $\mathrm{AD}$. The adverse effects of virgin microplastics on the fertilization and larval development of sea urchins. Mar. Environ. Res. 2017;130:69-76.

9. Fossi MC, Panti C, Guerranti C, et al. Are baleen whales exposed to the threat of microplastics? A case study of the Mediterranean fin whale (Balaenoptera physalus). Mar. Pollut. Bull. 2012;64:2374-2379.

10. Ziková A, Lorenz C, Hoffmann F, et al. Endocrine disruption by environmental gestagens in amphibians-A short review supported by new in vitro data using gonads of Xenopus laevis. Chemosphere 2017;181:74-82.

11. Carbery M, O’Connor W, Palanisami T. Trophic transfer of microplastics and mixed contaminants in the marine food web and implications for human health. Environ. Int. 2018;115:400-409.

12. Karami A, Golieskardi A, Choo CK, Larat V, Galloway TS, Salamatinia B. The presence of microplastics in commercial salts from different countries. Sci. Rep. 2017;7:46173.

13. Yousif E, Haddad R. Photodegradation and photostabilization of polymers, especially polystyrene: Review. Springerplus 2013;2:1-32.

14. Park SY, Kim CG. Biodegradation of micro-polyethylene particles by bacterial colonization of a mixed microbial consortium isolated from a landfill site. Chemosphere 2019;222:527-533.

15. Chtourou H, Riedl B, Kokta BV. Surface modification of polyethylene pulp fiber by ozone treatment. An analytical and thermal characterization. Polym. Degrad. Stab. 1994;43:149-156.

16. Behin J, Farhadian N, Ahmadi M, Parvizi M. Ozone assisted electrocoagulation in a rectangular internal-loop airlift reactor: Application to decolorization of acid dye. J. Water Process Eng. 2015;8:171-178.

17. Liu P, Qian L, Wang $\mathrm{H}$, et al. New insights into the aging behavior of microplastics accelerated by advanced oxidation processes. Environ. Sci. Technol. 2019;53:3579-3588.

18. Gongjian B, Yunxuan W, Xingzhou H. Surface modification of polyolefine by UV light/ozone treatment. J. Appl. Polym. Sci. 1996;60:2397-2402.

19. Hankett JM, Welle A, Lahann J, Chen Z. Evaluating UV/H2O2 exposure as a DEHP degradation treatment for plasticized PVC. J. Appl. Polym. Sci. 2014;131:

20. Mao R, Lang M, Yu X, Wu R, Yang X, Guo X. Aging mechanism of microplastics with UV irradiation and its effects on the adsorption of heavy metals. J. Hazard. Mater. 2020;393:122515.

21. Tofa TS, Kunjali KL, Paul S, Dutta J. Visible light photocatalytic degradation of microplastic residues with zinc oxide nanorods. Environ. Chem. Lett. 2019;17:1341-1346.

22. Gardette M, Perthue A, Gardette JL, et al . Photo- and thermal-oxidation of polyethylene: Comparison of mechanisms and influence of unsaturation content. Polym. Degrad. Stab. 2013;98:2383-2390.

23. Lu Z, Yin R, Yao J, Leung CKY. Surface modification of polyethylene fiber by ozonation and its influence on the mechanical properties of Strain-Hardening Cementitious Composites. Compos. Part B Eng. 2019;177:107446.

24. Nishiyama T, Matsuura K, Sato E, Kometani N, Horibe H. Degradation of hydrophilic polymers in aqueous solution by using ozone microbubble. J. Photopolym. Sci. Technol. 2017;30: 285-289.

25. Bader H. Determination of ozone in water by the indigo method: a submitted standard method. Ozone. Sci. Eng. 1982;4:169-176.

26. Hoigné J, Bader H, Haag WR, Staehelin J. Rate constants of reactions of ozone with organic and inorganic compounds in water-III. Inorganic compounds and radicals. Water Res. 1985;19:993-1004.

27. Liu CZ, Wu JQ, Ren LQ, Tong J, Li JQ, Cui N, Brown NMD, Meenan BJ. Comparative study on the effect of RF and DBD plasma treatment on PTFE surface modification. Mater. Chem. Phys. 2004;85:340-346.

28. Staehelin J, Hoigne J. Decomposition of ozone in water: rate of initiation by hydroxide ions and hydrogen peroxide. Environ. Sci. Technol. 1982;16:676-681.

29. Stark NM, Matuana LM. Surface chemistry changes of weathered HDPE/wood-flour composites studied by XPS and FTIR spectroscopy. Polym. Degrad. Stab. 2004;86:1-9.

30. Zerbi G, Gallino G, Del Fanti N, Baini L. Structural depth profiling in polyethylene films by multiple internal reflection infra-red spectroscopy. Polymer (Guildf). 1989;30:2324-2327.

31. Chtourou H, Riedl B, Kokta BV, Adnot A, Kaliaguine S. Synthetic pulp fiber ozonation: An ESCA and FTIR study. J. Appl. Polym. Sci. 1993;49:361-373. 
32. Peeling J, Clark DT. Surface ozonation and photooxidation of polyethylene film. J. Polym. Sci. Polym. Chem. Ed. 1983;21:2047-2055.

33. Kefeli AA, Razumovskii SD, Zaikov GY. Interaction of polyethylene with ozone. Polym. Sci. USSR. 1971;13:904-911.

34. Gu H, Wu J, Doan H. Hydrophilicity Enhancement of HighDensity Polyethylene Film by Ozonation. Chem. Eng. Technol. 2009;32:726-731.

35. Patel D, Wu J, Chan P, Upreti S, Turcotte G, Ye T. Surface modification of low density polyethylene films by homogeneous catalytic ozonation. Chem. Eng. Res. Des. 2012;90:1800-1806.

36. Tidjani A. Comparison of formation of oxidation products during photo-oxidation of linear low density polyethylene under different natural and accelerated weathering conditions. Polym. Degrad. Stab. 2000;68:465-469.

37. Yamauchi J, Yamaoka A, Ikemoto K, Matsui T. Reaction mechanism for ozone oxidation of polyethylene as studied by ESR and IR spectroscopies. Bull. Chem. Soc. Jpn. 1991;64:1173-1177. 38. Billamboz N, Grivet M, Foley S, Baldacchino G, Hubinois J-C. Radiolysis of the polyethylene/water system: Studies on the role of hydroxyl radical. Radiat. Phys. Chem. 2010;79:36-40.

39. Jabarin SA, Lofgren EA. Photooxidative effects on properties and structure of high-density polyethylene. J. Appl. Polym. Sci. 1994;53:411-423.

40. Luongo JP. Infrared study of oxygenated groups formed in polyethylene during oxidation. J. Polym. Sci. 1960;42:139-150.

41. Gugumus F. Contribution to the photolysis of hydroperoxides in polyethylene. Polym. Degrad. Stab. 1990;27:19-34.

42. White CH, Gough RH, McGregor JU, Vickroy VV. Ozonation effect on taste in water packaged in high density polyethylene bottles. J. Dairy Sci. 1991;74:96-99.

43. Wypych G. Handbook of material weathering. $6^{\text {th }}$ ed. Elsevier. Ontario: ChemTec Publishing; 2018. 